Thorax (1970), 25, 708.

\title{
Clinical aspects of blastomycosis
}

\author{
RICHARD P. O'NEILL and ROBERT W. B. PENMAN \\ Department of Medicine, University of Kentucky Medical Center, Lexington, Kentucky
}

\begin{abstract}
Blastomycosis is a specific granulomatous disease which tends to be chronic and indolent. It frequently presents in extrapulmonary form by means of haematogenous dissemination from the lungs. It has been shown that tuberculosis, histoplasmosis and coccidioidomycosis are, in the majority of cases, mild and subclinical in effect and often heal without therapy. It is probable that blastomycosis behaves in a like manner. The exact mortality is not known but is probably in the range of $13 \%$ in hospitalized cases with disseminated disease (Blastomycosis Cooperative Study of the Veterans Administration, 1964). The most effective form of therapy in active disease is amphotericin B ; 2-hydroxy-stilbamidine is also used.

Blastomycosis has largely been considered to be a disease of the American continent. However, cases have been reported from Africa and Europe and therefore a wider appreciation of this disease is considered pertinent. The relevant literature has been reviewed and four illustrative cases are presented.
\end{abstract}

North American blastomycosis was first described by Gilchrist in 1896 in a report of a case which had previously been diagnosed as 'pseudolupus vulgaris' and had been thought to be tuberculous in origin. Gilchrist showed that the disease was caused by a specific organism, Blastomyces dermatitidis. This is now known to be a biphasic fungus which grows as a mould at $20^{\circ} \mathrm{C}$. on a variety of media and as a yeast at $37^{\circ} \mathrm{C}$. on media containing non-coagulated protein. The yeast or tissue phase reveals, on microscopical examination, round cells, 8 to $25 \mu$ in diameter with thick refractile walls. Budding is characteristically single and broad based.

\section{GEOGRAPHICAL DISTRIBUTION}

The disease was previously thought to be restricted to the North American continent. ('European blastomycosis' is a misnomer and is, in reality, cryptococcosis.) The areas of highest incidence appear to be in the Mississippi-Ohio river basins and in the middle Atlantic states. Kentucky has the highest frequency of all states with a total of over 200 (Furcolow, Balows, Menges, Pickar, McClellan, and Saliba, 1966) reported cases. The endemic areas are the western and central parts of the state, with apparent sparing of the mountainous eastern sector. Human cases have been reported in 61 of the 120 counties in Kentucky and canine cases in 11. The exact incidence is not known but probably approximates 6 cases per
100,000 population (Furcolow et al., 1966). However, recent studies have shown previously unrecognized, widely separated areas of endemic blastomycosis. Seven cases have been reported from Africa; two from the Congo (Gatti, Renoirte, and Vandepitte, 1964 ; Gatti, De Broe, and Ajello, 1968) ; one each from the Republic of South Africa and from Uganda (Emmons, Murray, Lurie, King, Tulloch, and Connor, 1964); one from Tunisia (Vermeil, Gordeeff, and Haddad, 1954); two from Tanzania (Jelliffe, Hutt, Connor, King, and Lunn, 1964 ; Mackay, 1964). Wegmann (1952) reported a case from Switzerland with a positive skin test and complement fixation titre, although $B$. dermatitidis was not cultured from the sputum. The patient had worked in a tobacco factory which processed tobacco from the United States. Dowling and Elworthy (1926) reported a case from Britain with smears and cultures apparently positive for $B$. dermatitidis ; this patient also had a history of close contact with materials shipped from the United States. A wider appreciation of this disease is therefore considered pertinent.

\section{EPIDEMIOLOGY}

The organism has not been isolated from sources in nature other than for a single report (Denton, McDonough, Ajello, and Ausherman, 1961). B. dermatitidis has been grown on artificially infected garden soil (Emmons, 1951) and on tree bark 
(Menges, Furcolow, Larsh, and Hinton, 1952). Although there is no proof that soil is the source of infection, the evidence is suggestive. The majority of cases are sporadic but an epidemic of 11 cases has been reported from North Carolina (Smith, Harris, Conant, and Smith, 1955).

\section{PATHOGENESIS}

Because of its most prominent manifestations blastomycosis has long been considered a primary disease of the skin. In the majority of cases this impression is erroneous. It is in fact an inhalation infection and the prime target organ is the lung (Furcolow et al., 1966 ; Baum and Schwarz, 1959; Blastomycosis Cooperative Study of the Veterans Administration, 1964). Thus, the lungs were involved in at least $95 \%$ of the cases in which necropsy has been performed (Martin and Smith, 1939; Wade and Bel, 1916). It may later disseminate by the haematogenous route to various sites in the body but pulmonary blastomycosis is frequently found without skin lesions or other organ involvement.

Inhalation of the fungus produces an inflammatory reaction with granuloma formation and the exudation of inflammatory cells, predominantly polymorphonuclear leucocytes. The primary lesion is in many ways similar to tuberculosis or histoplasmosis in that a 'Ghon complex' is produced with parenchymal infiltration, lymphangitis and lymphadenitis (Newberne, Neal, and Heath, 1955; Robbins, 1954). It is probable that the majority of such lesions undergo primary organization and healing, the end result of which is a small fibrotic scar (Gilchrist, 1896 ; Baum and Schwarz, 1959). On the other hand, the disease may, in the primary stage, evolve and give rise to acute bronchopneumonia, acute lobar pneumonia, miliary lesions in the lung or haematogenous spread. The acute primary stage may progress to a more chronic type of infection, manifesting itself as a pyogenic process with a tendency to suppuration and the formation of small microabscesses. There is little evidence of caseation, as distinct from tuberculosis, and blastomycosis also differs from the latter in its greater tendency toward healing by fibrosis and absorption. This aspect is important for it helps to explain the frequent observation of cutaneous disease without apparent pulmonary involvement. Relapse may occur following arrested subclinical primary infection. This is considered by most authorities to be endogenous reinfection rather than exogenous.
In such a case the pathological process is essentially that of the primary stage but without lymphadenitis and lymphadenopathy.

The blastomycete is most often found in areas of suppuration or within giant cells in close proximity to necrotic areas. The organism is found in the tissues in the yeast and not in the mycelial phase. In disseminated disease, the pathological reaction is that seen in the lung, namely inflammatory, suppurative, necrotic and fibrotic and not infrequently with sinus tract formation. In rare cases primary blastomycosis of the skin may occur, as it has developed in laboratory workers following inoculation through the skin (Wilson, Cawley, Weidman, and Gilmer, 1955) where a local chancre was accompanied by lymphangitis or lymphadenitis or both. In disseminated blastomycosis with metastases to the skin, lymphadenitis and lymphadenopathy are conspicuously absent.

The mode of infection is not known and there is no evidence that the disease is transmitted from animal to animal, from animal to man or from man to man (Smith, 1947).

\section{AGE, SEX AND RACE}

Blastomycosis can occur at any age. It has been reported in a 6-month-old girl (Rosenthal, 1935) and in a patient in the ninth decade (Schwarz and Baum, 1951), but the peak incidence probably occurs in young and middle-aged adults. Thirtyfour per cent of Baum's patients were in the age group under 40 and only $12 \%$ were over 60 years of age (Baum and Schwarz, 1959). However, 37\% of the patients previously referred to in the Kentucky study were 60 and above (Furcolow et al., 1966). This later age incidence may reflect delay in making the diagnosis or in seeking out medical advice. Most studies report on the marked prevalence of the disease in males. Thus, the ratio of male to female patients, from a number of studies, including that of Baum and Schwarz (1959), averages $9: 1$, varying from a reported low $6: 1$ (Furcolow et al., 1966) to a high of 15:1 (Blastomycosis Cooperative Study of the Veterans Administration, 1964). In view of the suspected prevalence of the organism in the soil the higher incidence in males most probably reflects occupational status, i.e., agricultural work. There is no definite racial predilection, though there is a suggestion that the disease may be somewhat more common among Negroes (Baum and Schwarz, 1959). 


\section{CLINICAL ASPECTS}

The clinical manifestations of blastomycosis depend on the organ or organs involved. The classical view is to subdivide the disease into two groups, cutaneous and disseminated. However, as pointed out, cutaneous involvement is most frequently a manifestation of disseminated disease and hence this classification fails to recognize this fact. It would seem more appropriate to think of blastomycosis in much the same light as tuberculosis, histoplasmosis or cryptococcosis - that the disease is primarily a disease of the lungs and that all other manifestations stem from pulmonary involvement. The same concept prompts the subdivision of blastomycosis into (1) asymptomatic or subclinical disease and (2) symptomatic or clinical disease which is $(a)$ localized to the lungs, or $(b)$ disseminated beyond the lungs to bone, skin or meninges.

Thus, it is highly likely that there is a relatively common subclinical form, as in other forms of granulomatous disease of the lungs, such as tuberculosis or histoplasmosis. In such a case, a primary asymptomatic 'Ghon' focus is produced following inhalation of the blastomycete. This undergoes healing and results in a small fibrotic scar with or without calcification.

The picture of clinical or symptomatic pulmonary blastomycosis is non-specific. Pulmonary blastomycosis is less commonly recognized than the cutaneous form. However, it must be stressed that in most cases of skin involvement a pulmonary lesion can be found, a fact which further points up the numerous cases of asymptomatic pulmonary disease. The pulmonary disease is frequently chronic and indolent but acute symptoms may occur with fever, malaise and myalgia suggestive of influenza. Acute primary and reinfection pulmonary blastomycosis has been noted presenting as an acute toxic illness with fever, malaise, chest pain and cough productive of mucopurulent sputum, and showing radiographic evidence of pulmonary infiltrates, bronchopneumonia or lobar consolidation (Smith et al., 1955 ; Baker, Warrick, and Noojin, 1952 ; Watson, Moore, and Blank, 1958). The North Carolina epidemic (Smith et al., 1955) demonstrated acute toxic symptoms and pulmonary infiltrates. In 10 of these 11 cases the only residual manifestation was a positive blastomycin skin test. Acute miliary involvement of the lung has been described in seven cases (Blastomycosis Cooperative Study of the Veterans Administration, 1964) and is radiographically identical with miliary tuberculosis or histoplasmosis. Chronic pulmonary blastomycosis would seem, in the main, to be due to endogenous reinfection. The patient tends to become chonically ill and debilitated and may have non-specific symptoms of laryngitis, bronchitis and/or pneumonitis with fever, night sweats, hoarseness, chronic cough productive of mucopurulent sputum, haemoptysis, chest pain and dyspnoea.

Because of the variety of the pulmonary manifestations the chest radiograph is non-specific. The disease may occur anywhere in the lungs, but especially in the posterior segments of the upper lobes where the most common lesion is the infiltrative granulomatous variety. However, nodular, fibrotic, reticulo-nodular, pneumonic, miliary and cavitary lesions are also seen. Previous work has stated that cavitary lesions are rare and small and do not have prominent walls (Baum and Schwarz, 1959 ; Martin and Smith, 1939 ; Hawley and Felson, 1956). Our experience and that of others indicate that cavities of varying size, from less than $1 \mathrm{~cm}$. to $8 \mathrm{~cm}$. in diameter, occur in approximately $25 \%$ of patients with pulmonary lesions (Blastomycosis Cooperative Study of the Veterans Administration, 1964 ; Cherniss and Waisbren, 1956 ; Abernathy, 1959 ; Kunkel, Weed, McDonald, and Clagett, 1954 ; Feld and Cadden, 1949). Hilar and/ or mediastinal lymphadenopathy with or without parenchymal lesions are not infrequent. A suggestive radiological feature of blastomycosis is dense, fibrous pleura, usually without extensive calcification and without major accumulation of pleural effusion (Baum and Schwarz, 1959; Kunkel et al., 1954). Pleural effusion without pleural thickening may also be seen (Blastomycosis Cooperative Study of the Veterans Administration, 1964), but this is somewhat unusual.

Finally, laryngitis and bronchitis may occur and bronchoscopic examination has revealed marked inflammation and small endobronchial ulcers (Weisel and Landis, 1953).

Skin lesions are the most common forms of extrapulmonary blastomycosis and are the most usual presenting feature. Approximately $25 \%$ of patients have obvious skin lesions at the time hospitalization is sought and in most instances they represent disseminated disease. The sites most commonly affected are exposed, peripheral areas such as the hand, wrist, lower leg and the face. However, lesions can occur in virtually any area of the skin and have been described on the trunk in unexposed regions. The lesions may be single or multiple. The process begins as a subcutaneous nodule which progresses to a papulo- 
pustule that slowly enlarges and eventually ulcerates. The ulcer is usually covered by the crusty, heaped-up appearance of 'proud-flesh' which, when lifted, shows a hyperaemic granulomatous base with characteristic 'black dots' (Leavell, 1965). The edge of the lesion is heaped up and undermined with small micro-abscesses in which the organism is found. The ulcer heals by fibrosis and cicatrix from the centre. Lymphadenitis or lymphadenopathy is not seen in the secondary or disseminated cutaneous form. Crops of new skin lesions are indicative of active pulmonary disease (Baum and Schwarz, 1959). The differential diagnosis of the skin lesion should include South American blastomycosis, coccidioidomycosis, actinomycosis, tuberculosis verrucosa cutis, carcinoma and hidradenitis suppurativa. Erythema nodosum has been described in 3 of 11 patients with acute blastomycosis (Smith et al., 1955).

Contrary to some belief (Bunge and Harness, 1951), the genitourinary tract is frequently involved in disseminated blastomycosis. The incidence varies in published reports from $4.4 \%$ (Blastomycosis Cooperative Study of the Veterans Administration, 1964) to $22 \%$ (Kunkel et al., 1954). Epididymitis, typically with recurrent episodes, would appear to be the most common presenting feature. The epididymis becomes swollen and tender and there may be some underlying involvement of the testis. A not uncommon finding is scrotal ulcer or draining sinus that appears following recurrent episodes of epididymitis or orchitis. If the prostate is involved it may be found to be enlarged, boggy and slightly tender. Renal blastomycosis may occur as isolated genitourinary disease with granulomatous and/or necrotic suppurative lesions in either the cortex or the medulla (Stober, 1914) or may be associated with prostatic infection (Baum and Schwarz, 1959 ; Bechtel and LeCount, 1914 ; Krost, Stober, and Moes, 1914; Riley and LeCount, 1914; Eisentaedt and Boughton, 1914).

Bone lesions are seen in systemic disease with considerable frequency. A review of the literature indicates that there is osseous involvement in at least $30 \%$ of cases (Martin and Smith, 1939; Kunkel et al., 1954), an incidence which is in general agreement with our experience. The bone is involved by haematogenous dissemination. A suppurative osteomyelitis is set up most frequently at the epiphyseal end of long bones. Occasional rupture through the epiphyseal plate occurs with the production of a suppurative arthritis. Associated abscesses and draining sinuses are common. The radiological picture is quite non-specific and shows an osteolytic process not infrequently surrounded by some osteoblastic reaction.

The central nervous system is involved by haematogenous dissemination. Meningitis, meningo-encephalitis, transverse myelitis, cerebral or cerebellar abscesses, and epidural abscess have all been described (Martin and Smith, 1939; Wade and Bel, 1916; Stober, 1914; Riley and LeCount, 1914 ; Craig, Dockerty, and Harrington, 1940 ; Friedman and Signorelli, 1946 ; Greenwood and Voris, 1950; Myers and Stober, 1914). The incidence varies from $3.75 \%$ (Cherniss and Waisbren, 1956) to 10\% (Baum and Schwarz, 1959) and as a general rule the prognosis is poor.

Thus, blastomycosis may involve virtually any organ in the body including, rarely, the adrenals (Baum and Schwarz, 1959; Martin and Smith, 1939) and the gastro-intestinal tract (Vinson, Broders, and Montgomery, 1928 ; Chick, Sutliff, Rakich, and Furcolow, 1956). The liver and spleen also are not infrequently enlarged in miliary disseminated disease.

There does not seem to be an increased incidence of blastomycosis in debilitating diseases (diabetes mellitus, lymphoma, blood dyscrasias, etc.) or with steroid administration, as is reported in cryptococcosis (Butler, Alling, Spickard, and Utz, 1964), but where blastomycosis co-exists with these conditions a thorough search must be made for disseminated disease. It is important to note that blastomycosis may co-exist with other diseases, such as pulmonary tuberculosis or bronchogenic carcinoma (Blastomycosis Cooperative Study of the Veterans Administration, 1964 ; O'Neill and Furcolow, unpublished data).

\section{DIAGNOSIS}

The diagnosis of blastomycosis demands that this entity be considered in the differential diagnosis of granulomatous disease and that the clinicians have some knowledge of its various manifestations. The only diagnostic finding is $B$. dermatitidis on culture. There has, in the past, been confusion with other organisms, such as Cryptococcus neoformans and occasionally Histoplasma capsulatum. The risk of confusion is less if the characteristic broad-based 'budding' is looked for. Sufficient diagnostic use of smears and cultures other than sputum is frequently not made. $\mathrm{KOH}$ mounts of gastric aspirate, urine, pus, prostatic secretions, blood, bone marrow and abdominal fluid prompt the diagnosis in many instances, and subsequent culture of such specimens clinches the issue from 50 to $80 \%$ of the cases (Blastomycosis Coopera- 


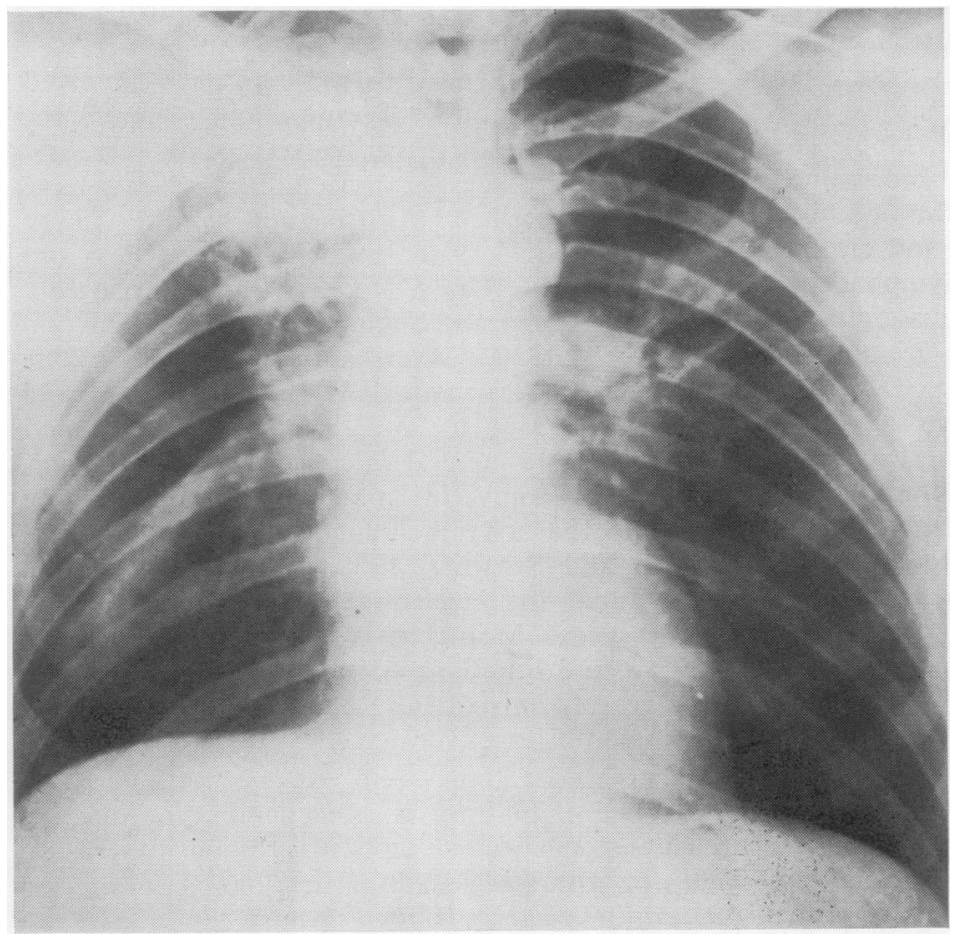

FIG. 1. Mass lesion in right upper lobe very suggestive of bronchogenic carcinoma. A 53-year-old white man presented four months prior to admission with an ulcer of the right leg which was diagnosed as blastomycosis. He was not treated at that time. He was later admitted because of a productive cough, weight loss and this chest radiograph. Sputum cultures were positive for $\mathrm{B}$. dermatitidis. The chest lesion cleared with amphotericin B treatment.

FIG. 2. Apical fibro-cavitary disease simulating tuberculosis. This 24-year-old white man was admitted with bilateral apical infiltrations and a cavity in the left upper lobe. Sputum cultures were positive for $\mathrm{B}$. dermatitidis and negative for Mycobacterium tuberculosis. Blastomycin complement fixation was also positive in high titre. He made an excellent response to amphotericin $B$ treatment.

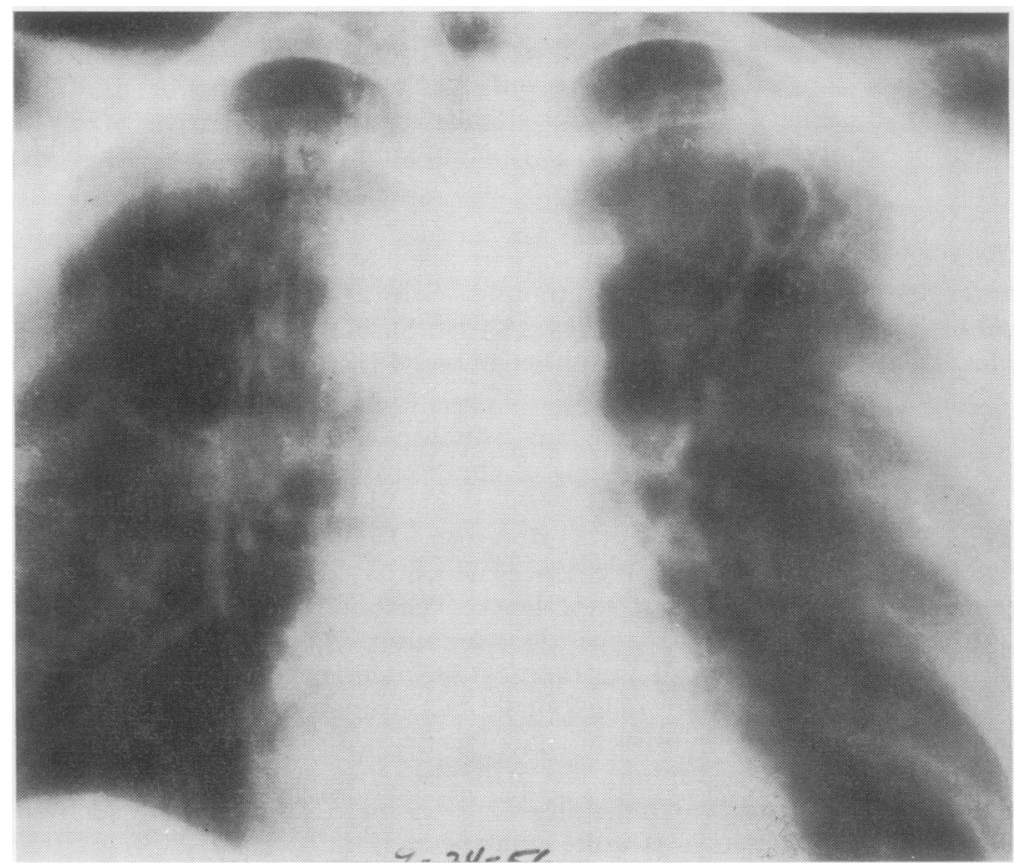




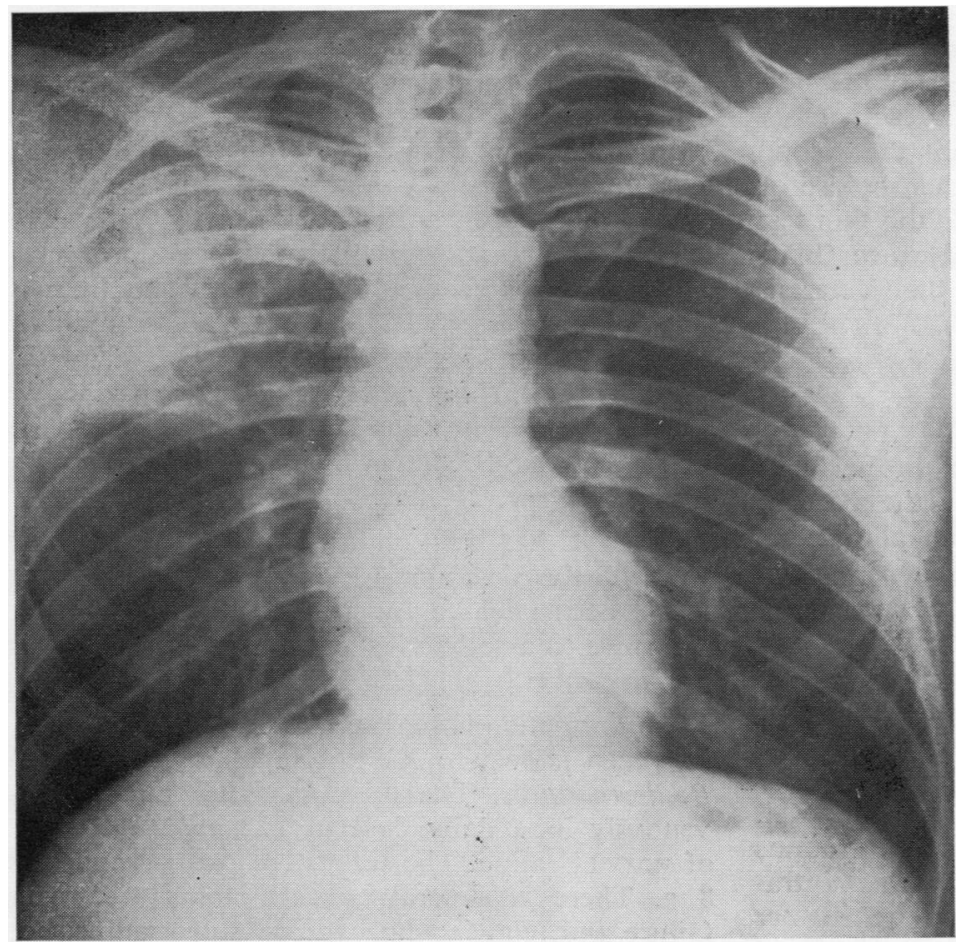

FIG. 3. Lobar pneumonia. A 42-yearold Negro man was admitted with right pleuritic chest pain, cough, sputum production, haemoptysis and low-grade fever. Sputum cultures were positive for B. dermatitidis. Pneumonia cleared completely with amphotericin $B$ treatment.

FIG. 4. Miliary disease. A 46-yearold Negro man had prostatitis. The prostate was massaged and the secretions were cultured, later growing B. dermatitidis. Fortyeight hours later the patient had fever, chills and dyspnoea. A chest radiograph (right) showed this miliary picture. He was treated with amphotericin $B$ and within two weeks the miliary disease had completely resolved radiographically.

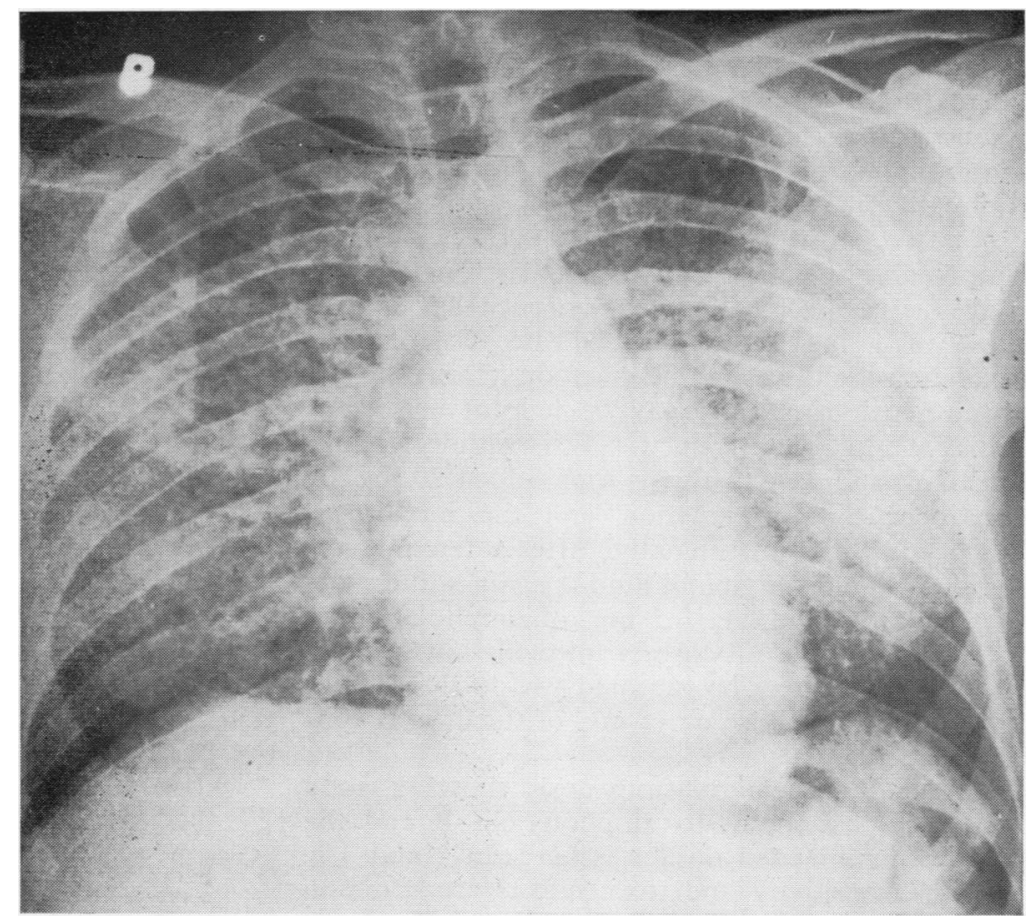


tive Study of the Veterans Administration, 1964), Skin tests, complement fixation and precipitin tests are unreliable, being positive in less than $50 \%$, and frequently exhibit cross-reactivity with other fungal antigens. It is most important that blood for serological studies be drawn either before or at the time of placing of skin tests, as the skin test antigen can cause a rise in antibody titre (Blastomycosis Cooperative Study of the Veterans Administration, 1964 ; Louria, 1967).

\section{TREATMENT}

There have been significant advances in the treatment of the systemic mycoses over the past 10 years or so. Two new antifungal antibiotics, amphotericin B and X5079C, have appeared. However, it should be remembered that chemotherapy is only part of the treatment. General measures of nursing care, rest, good nutrition and appropriate surgical measures are still necessary.

Streptomyces nodosus is the source of amphotericin $B$, which is an amphoteric polyene antibiotic. It is both fungistatic and fungicidal. $B$. dermatitidis is sensitive to concentrations ranging from 0.03 to $1.0 \mathrm{mg} . / \mathrm{ml}$. in vitro. Intravenous injection of $10 \mathrm{mg}$. of amphotericin B per day initially, followed by a gradual increase of the daily dose to $0.65 \mathrm{mg}$. $/ \mathrm{kg}$. of the soluble preparation, yields peak blood levels of 0.5 to 3.5 $\mathrm{mg} . / \mathrm{ml}$. The drug does not accumulate in the circulation and urinary excretion is slow. The blood:spinal fluid concentration ratios of the antibiotic are 30:1 to 50:1 (Goodman and Gilman, 1965; Utz, 1963).

The recommended dose of amphotericin B for intravenous therapy is $025 \mathrm{mg} . / \mathrm{kg}$. on the first day, increasing by $0.25 \mathrm{mg} / \mathrm{kg}$. each day until a dose of $1 \mathrm{mg} . / \mathrm{kg}$. is reached. Because of slow excretion the drug may be given on alternate days. Intrathecal injections may be helpful in meningitis. A 5-ml. quantity of C.S.F. is withdrawn into a $20-\mathrm{ml}$. syringe ; to this is then added $20 \mathrm{mg}$. of hydrocortisone in solution and the mixture is slowly instilled intraspinally. After a few minutes a 5-ml. amount of spinal fluid is again withdrawn, a solution containing $0.5 \mathrm{mg}$. of amphotericin B is added and the mixture is injected slowly intrathecally: This may be repeated two to three times a week. A total dose of $15 \mathrm{mg}$. of the drug is considered adequate.

North American blastomycosis shows a good response in general to amphotericin $B$ and the total recommended dosage is between 2 and $3 \mathrm{~g}$.

Hypersensitivity and toxic effects are common and include flushing, anaphylaxis, thrombocytopenia, generalized pain, convulsions, chills, fever, phlebitis, anaemia, anorexia, and hepatocellular and renal dysfunction. Laboratory studies frequently show a rise in serum urea nitrogen, hypokalaemia and hypomagnesaemia. Renal biopsy and post-mortem studies have shown tubular degeneration and atrophy and proliferative glomerular changes with pericapsular fibrosis and nephrocalcinosis. Side-effects can be reduced to a significant degree by giving the patient 650 mg. of aspirin and $10 \mathrm{mg}$. of compazine 30 minutes before infusion and then delivering the amphotericin B intravenously admixed with hydrocortisone, $25 \mathrm{mg}$.

$\mathrm{X}-5079 \mathrm{C}$ has been under investigation for some years by the Veterans Administration and has not as yet been released for general use. It is difficult therefore to assess the efficacy of this drug at this time.

An aromatic diamidine, 2 hydroxy-stilbamidine, has been shown to have a suppressive effect on $B$. dermatitidis. The drug is administered intravenously in a daily dose of $225 \mathrm{mg}$. in $500 \mathrm{ml}$. of normal saline. The total dose recommended is $8 \mathrm{~g}$. There is general concern about treatment failure and relapse with hydroxy-stilbamidine, but Lockwood, Busey, Blair, and Allison (1962) report good results. Four patients illustrating different aspects of the disease are now presented.

We wish to thank Professors M. L. Furcolow and E. W. Chick for helpful advice and criticism.

This study was supported in part by $\mathrm{NIH}$ grant no. HE-08932.

\section{REFERENCES}

Abernathy, R. S. (1959). Clinical manifestations of pulmonary blastomycosis. Ann. intern. Med., 51, 707.

Baker, R. D. Warrick, G. W., and Noojin, R. O. (1952). Acute blastomycotic pneumonia: report of a fatal case of twenty days duration. Arch. intern. Med., 90, 718.

Baum, G. L., and Schwarz, J. (1959). North American blastomycosis. Amer. J. med. Sci., 238, 661 .

Bechtel, R. E., and LeCount, E. R. (1914). A case of systemic blastomycosis with necropsy. Arch. intern. Med., 13, 609.

Blastomycosis Cooperative Study of the Veterans Administration (1964). Blastomycosis. A review of 198 cases. Amer. Rev. resp. Dis., 89, 659.

Bunge, R. G., and Harness, W. N. (1951). Blastomycosis of the prostate: case report. J. Urol. (Baltimore), 66, 263.

Butler, W. T., Alling, D. W., Spickard, A., and Utz, J. P. (1964) Diagnositc and prognostic value of clinical and laboratory findings in cryptococcal meningitis. New Engl. J. Med., 270, 59.

Cherniss, E. I., and Waisbren, B. A. (1956). North American blastomycosis: a clinical study of $\mathbf{4 0}$ cases. Ann. intern. Med., 44, 105.

Chick, E. W., Sutliff, W. D., Rakich, J. H., and Furcolow, M. L. (1956). Epidemiological aspects of cases of blastomycosis ad mitted to Memphis, Tennessee, hospitals during the period 19221954: a review of 86 cases. Amer. J. med. Sci., $231,253$.

Craig, W. McK., Dockerty, M. B., and Harrington, S. W. (1940) Intravertebral and intrathoracic blastomycoma simulating dumb-bell tumor. Sth. Surg., 9, 759. 
Denton, J. F., McDonuugh, E. S., Ajello, L., and Ausherman, R. J. (1961). Isolation of Blastomyces dermatitidis from soil. Science, $133,1126$.

Dowling, G. B., and Elworthy, R. R. (1926). Case of blastomycetic dermatitis (Gilchrist). Proc. roy. Soc. Med., 19, Section of Dermatology, p. 4.

Eisentaedt, J. S., and Boughton, T. H. (1914). A case of systemic blastomycosis. Arch. intern. Med., 13, 617.

Emmons, C. W. (1951). The isolation from soil of fungi which cause disease in man. Trans. N.Y. Acad. Sci., 14, 51 .

- Murray, I. G., Lurie, H. I., King, M. H., Tulloch, J. A., and Connor, D. H. (1964). North American blastomycosis: two autochthonous cases from Africa. Sabouraudia, 3, 306.

Feld, D. D., and Cadden, A. V. (1949). Systemic blastomycosis. Dis. Chest., 16, 473 .

Friedman, L. L., and Signorelli, J. J. (1946). Blastomycosis: a brief review of the literature and a report of a case involving the review of the literature and a report
meninges. Ann. intern. Med., 24, 385 .

Furcolow, M. L., Balows, A., Menges, R. W., Pickar, D., McClellan, J. T., and Saliba, A. (1966). Blastomycosis: an importan medical problem in the central United States. J. Amer. med. Ass., 198, 529 .

Gatti, F., De Broe, M., and Ajello, L. (1968). Blastomyces dermatitidis infection in the Congo. Report of a second autochthonous case. Amer. J. trop. Med. Hyg., 17, 96.

- Renoirte, R., and Vandepitte, J. (1964). Premier cas de blastomycose nord-américaine observé au Congo (Loépoldville). Ann. Soc. Belge med. Trop., 44, 1057.

Gilchrist, T. C. (1896). A case of blastomycetic dermatitis in man. Johns Hopk. Hosp. Rep., 1, 269.

Goodman, L. S., and Gilman, A. (1965). The Pharmacological Basis of Therapeutics, 3rd ed., Macmillan New York.

Greenwood, R. C., and Voris, H. C. (1950). Systemic blastomycosis with spinal cord involvement. J. Neurosurg., 7, 450.

Hawley, C., and Felson, B. (1956). Roentgen aspects of intrathoracic blastomycosis. Amer. J. Roentgenol., 75, 751.

Jelliffe, D. B., Hutt, M. S. R., Connor, D. H., King, M. H., and Lunn, H. F. (1964). Report of a clinico-pathological conference from Mulago, July 30, 1963. E. Afr. med. J., 41, 79.

Krost, R. A., Stober, A. M., and Moes, M. J. (1914). A case of systemic blastomycosis. Arch. intern. Med., 13, 557.

Kunkel, W. M. Jr., Weed, L. A., McDonald, J. R., and Clagett, O. T. (1954). North American blastomycosis-Gilchrist's disease: a clinicopathologic study of ninety cases. Int. Abstr. Surg., 99, 1.

Leavell, U. W., Jr. (1965). Cutaneous North American blastomycosis and black dots. Arch. Derm., 92, 155.

Lockwood, W. R., Busey, J. F., Blair, B. E., and Allison, F., Jr. (1962). The preferred treatment of blastomycosis with 2-hydroxystilbamidine. Clin. res., 10, 60.
Louria, D. B. (1967). Deep-seated mycotic infections, Allergy to fungi and mycotoxins. New Engl. J. Med., 277, 1065.

Mackay, J. P. (1964). Quoted from Emmons et al. Sabouraudia, 3, 306.

Martin, D. S., and Smith, D. T. (1939). Blastomycosis: II. A report of thirteen new cases. Amer. Rev. Tuberc., 39, 488.

Menges, R. W., Furcolow, M. L., Larsh, H. W., and Hinton, A. (1952). Laboratory studies of histoplasmosis. J. infect. Dis., 90, 67.

Myers, H. J., and Stober, A. M. (1914). A case of systemic blastomycosis. Arch. intern. Med., 13, 585.

Newberne, J. W. Neal, J. E, and Heath, M. K. (1955). Some clinical and microbiological observations on four cases of canine blastomycosis. J. Amer. vet. med. Ass., 127, 220.

O'Neill, R. P., and Furcolow, M. L. Unpublished data.

Riley, F. B., and LeCount, E. R. (1914). A case of systemic blastomycosis. Arch. intern. Med., 13, 614.

Robbins, E. S. (1954). North American blastomycosis in the dog. J. Amer. vet. med. Ass., 125, 391.

Rosenthal, J. M. (1935). Blastomycosis in an infant six months old. J. Lab. clin. Med., 20, 1164

Schwarz, J., and Baum, G. L. (1951). Blastomycosis. Amer. J. clin Path., 21, 999.

Smith, D. T. (1947). Fungus Diseases of the Lungs. Thomas, Springfield, Illinois.

Smith, J. G., Harris, J. S., Conant, N. F., and Smith, D. T. (1955) An epidemic of North American blastomycosis. J. Amer. med. Ass., 158, 641.

Stober, A. M. (1914). Systemic blastomycosis. A report of its pathological, bacteriological and clinical features. Arch. intern. Med., $13,509$.

Utz, J. P. (1963). Chemotherapeutic agents for the systemic mycoses. New Engl. J. Med., 268, 938.

Vermeil, C., Gordeeff, A., and Haddad, N. (1954). Sur un cas tunisien de mycose généralisée mortelle. Ann. Inst. Pasteur., 86, 636.

Vinson, P. P., Broders, A. C., and Montgomery, H. (1928). Blastomycosis of the esophagus: report of a case. Surg. Gynec. Obstet., 46, 255.

Wade, H. W., and Bel, G. S. (1916). A critical consideration of systemic blastomycosis. Arch. intern. Med., 18, 103.

Watson, S. H., Moore, S., and Blank, F. (1958). Generalzied North American blastomycosis. Canad. med. Ass. J., 78, 35.

Wegmann, T. (1952). Blastomykose und andere Pilzerkrankungen der Lunge. Dtsch. Arch. klin. Med., 199, 192.

Weisel, W., and Landis, F. B. (1953). Endobronchial lesions in pulmonary blastomycosis. J. thorac. Surg., 25, 570.

Wilson, J. W. Cawley, E. P., Weidman, F. D., and Gilmer, W. S. (1955). Primary cutaneous North American blastomycosis, Arch. Derm., 71, 39. 